\title{
Managing organizational trust - orientation towards trust in an
}

\author{
enterprise \\ Felicjan Bylok $^{\mathrm{a}^{*}}$, Piotr Tomski $^{a}$, Dorota Jelonek $^{a}$, Elzbieta Wyslocka $^{a}$ \\ ${ }^{a}$ Czestochowa University of Technology, Poland \\ *Corresponding author: Felicjan Bylok, Full Professor, bylokfelicjan@gmail.com
}

\begin{abstract}
.
The herein paper is a theoretical discussion on trust management in an enterprise and an empirical presentation of the role of a manager in terms of building trust in enterprises. In the first section, the authors at hand concentrate on various approaches to the definition of trust. However, in the second section they present the results of the empirical research on the chosen aspects of trust management in enterprises. The research conducted was aimed at outlining the intricate problematic issues of trust in organizations and constitutes a starting point for further research on the issue of trust management.
\end{abstract}

Key words: organizational trust, culture of trust, trust management, enterprises, manager

\section{Introduction}

The basis of cooperation is that of trust that is perceived as an important cultural and economic value of an enterprise. Trust appears when the values, missions and aims are shared by all the employees. Its development to a large extent depends on the manager who is required to display involvement and responsibility in activities that create trust. Enterprises that develop organizational trust receive a multitude of benefits. Thanks to trust, they may restrict the impact of formal mechanisms of control, which leads to the increase of the autonomy of employees. The consequence of the increase in trust is also the greater openness to new partners as cooperation with them may bring significant added value. Another positive effect is the reduction of uncertainty in cooperation with new partners.

\section{Trust in an enterprise - theoretical background}

Trust is present in many areas of social and economic life, with relation to which it is analysed from the viewpoint of various research perspectives. In sociology, it is perceived in the context of social actions that make these actions effective. It is defined as a type of bet 
placed on the uncertain and future actions of other people ${ }^{1}$. In economics, trust is perceived in the context of the theory of national choice. Trust is the relation of mutual calculations between the unit bestowing trust and the entity that trust is bestowed on $^{2}$. In the management, trust is deemed to be organizational value. Trust is the conviction that the action undertaken leads to the achievement of the goals set out and acquisition of benefits for all stakeholders ${ }^{3}$. A common element of all approaches is that of actions directed at other people. A source of trust in the actions of people may be that of familiarity, which results from the repetitiveness of interactions between parties or calculativeness associated with respecting the advantage of benefits over costs associated with relations or values referring to honesty and goodwill.

In subject-related literature, we may encounter various divisions of trust. An interesting typology of trust was presented by P. Kenning ${ }^{4}$ who distinguished general trust and specific trust. General trust is based on the cultural norm that requires trust in other entities or organizations. It is becoming its own form of culture of trust, namely, not only a social norm, yet also a value that is appreciated in society. However, specific trust relates to defined areas of social and economic life where agreements are made on the basis of trust. Such an area is an enterprise where the trust between stakeholders has a favourable impact on its functioning on the market. In this case, it is possible to refer to this as organizational trust.

Organizational trust is a specific type of trust in which the entity bestowing trust may be both internal and external stakeholders. In the first case, it appears in the relations between the various entities within the organization. It may also occur between the employee and an employee group. L. Cummings and P. Broomiley ${ }^{5}$, perceive trust in categories of the belief of the group members in terms of other groups which a) shall make every effort to adhere to the obligations accepted, b) proceed in an honest manner during the course of negotiations preceding the acceptance of obligations, c) do not take the opportunity to gain an advantage when the opportunity arises. While secondly between employees and managers and thirdly, between employees and the employer. J.A. Gilberth and T.L Tang ${ }^{6}$ write that organizational trust is the feeling of entrustment of the employer that involves the conviction that he/she shall adhere to the accepted obligations with regard to employees. Fourthly, between employees and the organization. T. Gillis ${ }^{7}$ defines organizational trust as the readiness of an organization that is based on behaviour and communication in relations and in actions entrust people or groups that are competent, open and honest, consistent, identify with the organizational aims, norms and values. Organizational trust also exists in the relation between the organization and its external stakeholders. Other organizations are listed among the 
important stakeholders. P.M. Doney and J.P. Cannon ${ }^{8}$ define trust with relation to B2B as the perceived credibility and benevolence of a target of trust.

\section{Management of trust in an enterprise}

The intricacy of the functioning of the contemporary enterprises requires a new approach in terms of its management. The processes that are characteristic of the "traditional" organization such as institutionalization, formalization and centralization do not regulate the internal life of an organization sufficiently. It is necessary to draw attention to the other organizational processes that favour the realization of organizational aims. One of such processes is that of trust management which bonds the various parts of an organization. By the term of trust management we shall perceive the activity of collecting, codifying, analysing and evaluating evidence relating to competence, honesty, security or dependability with the purpose of making assessments and decisions regarding trust relationships ${ }^{9}$. In turn, A. Jøsang $^{10}$ relate the term of trust management to on-line transactions, which according to them signify the activity of creating systems and methods that allow relying parties to make assessments and decisions regarding the dependability of potential transactions involving risk, and that also allow players and system owners to increase and correctly represent the reliability of themselves and their systems.

Trust management to a large extent relates to action associated with building trust. Building trust is a process that encompasses three stages ${ }^{11}$. In the first stage, trust is based on the profit and loss account. After establishing the benefits, what trust brings to the second party emerges. In the subsequent stage trust based on knowledge appears. This signifies the impact of knowledge between potential entities on the level of trust. The greater the knowledge about themselves at their disposal, the greater the trust potential shall be. In the final stage trust is based on the identification of partners involving the situation in which both parties adopt a mutual identity and each party may represent the interests of the other.

\section{Orientation towards trust in enterprises in light of self-analysis}

The authors at hand undertook the task of analysing the role of a manager in creating the orientation towards trust. With this aim in mind, the following research questions were formulated: Are there differences between the level of trust between the managers and employees in the analysed enterprises? To what extent does the size of an enterprise have an impact on the orientation of managers towards creating trust and orientation towards building 
the culture of trust? What factors of organizational trust influence the level of trust? In the search for answers to these questions, a survey method was availed of with the technique of an opinion poll. The research was conducted in 2015 and 161 enterprises participated in it. The selection of enterprises for research was based on the probability-quota sampling method. The research was conducted on owners, managers and employees of micro-sized enterprises (40), small enterprises (43), medium-sized enterprises (40) and large enterprises (38) in the province of Silesia.

One of the aims of the research was to identify of the level of trust in co-workers and managers in the analysed enterprises. Analysis of the research results indicates that in spite of the fact that the indicators of the lack of trust in managers and in co-workers are at the same level, there are differences in the level of trust. Employees display greater trust in managers (33\%) than in co-workers (22\%). The variable of the analysed population of enterprises with regard to the level of trust in employees was the size of enterprises (Table 1). The correlation coefficient of Spearman between the level of trust in managers and in the majority of employees and the size of the enterprise amounted to $r_{s}=0,226$ (at $p=0,0$ ). The high level of trust occurred in small enterprises and in large enterprises, while the lowest level occurred in micro-sized enterprises. Likewise, the level of trust in employees is associated with the size of an enterprise. In this case, a large difference appeared in the level of trust between enterprises, namely, between micro-sized enterprises and large and small enterprises amounted to $18 \%$.

Table 1 - Trust in enterprises in percentage form

\begin{tabular}{|l|l|l|l|l|l|l|}
\hline \multirow{2}{*}{ Size of enterprise } & \multicolumn{3}{l|}{ Trust in co-workers } & \multicolumn{2}{l|}{ Trust in managers } \\
\cline { 2 - 8 } & Lacking & Limited & High & Lacking & Limited & High \\
\hline Total & 6 & 72 & 22 & 6 & 61 & 33 \\
\hline Micro & 5 & 65 & 30 & 0 & 68 & 32 \\
\hline Small & 4 & 84 & 12 & 9 & 51 & 40 \\
\hline Medium & 5 & 78 & 17 & 3 & 65 & 32 \\
\hline Large & 10 & 61 & 29 & 13 & 61 & 36 \\
\hline
\end{tabular}

Trust in an organization is dependent on a multitude of factors. One of the significant ones is that of the characteristics of the employees and managers. The characteristics of the employees are of particular importance in the case of lateral trust, namely, between employees. Analysis of the data presented in Table 2 indicates that the greatest impact on the level of trust in other employees are features such as being open, responsible and readiness to provide help, whereas the lowest impact on keeping secrets and mutual trust. Trust to a large extent is based 
on mutuality and confidentiality. If these two factors are at a low level, then employees have limited trust in each other.

Table 2 - Features of employees influencing the level of trust shown to them with relation to the size of an enterprise in percentage form

\begin{tabular}{|l|l|l|l|l|l|}
\hline Features & Total & Micro & Small & Medium & Large \\
\hline They are open & 78 & 90 & 42 & 68 & 78 \\
\hline They are trustworthy & 56 & 60 & 33 & 53 & 56 \\
\hline The majority of them can keep a secret & 44 & 35 & 27 & 43 & 44 \\
\hline They illustrate great skills & 66 & 75 & 30 & 67 & 66 \\
\hline They are responsible & 68 & 75 & 39 & 60 & 68 \\
\hline They are honest & 56 & 40 & 37 & 60 & 56 \\
\hline They have trust in the management & 60 & 70 & 36 & 45 & 60 \\
\hline They trust each other & 48 & 50 & 30 & 40 & 48 \\
\hline They are loyal & 53 & 47 & 31 & 50 & 53 \\
\hline They are ready to provide help & 75 & 67 & 42 & 72 & 75 \\
\hline
\end{tabular}

Interesting research results are provided by analysing the evaluation of the features of employees as determinants of trust with regard to the size of an enterprise. In the majority of the analysed enterprises the set of features determining a high level of trust is similar to the general results. The only noticeable differences occurred in the case of openness and trust with regard to managers that was at its highest in micro-sized firms and at its lowest in small firms.

A significant impact on the level of trust in an enterprise is exerted by the characteristics of the manager, particularly those that refer to trust in employees. The greatest impact is derived from self-improvement of knowledge $\left(\mathrm{r}_{\mathrm{s}}\right.$ Spearman $=0,400$, at $\left.\mathrm{p}=0,05\right)$ and a high tendency to trust others $\left(r_{s}=0,399\right.$, at $\left.p=0,05\right)$. The more managers illustrate a greater willingness towards the self-improvement of knowledge and a higher tendency to trust others, the more the level of trust grows in the organization. Employees observe that managers are worthy of trust. Other characteristics of managers also indicate this, e.g. the thinking that the majority of people are open $\left(r_{s}=0,254\right.$, at $\left.p=0,05\right)$, keeping secrets $\left(r_{s}=0,251\right.$, at $\left.p=0,05\right)$ and the conviction that trust is an important source of competitiveness $\left(\mathrm{r}_{\mathrm{s}}=0,251\right.$, at $\left.\mathrm{p}=0,05\right)$. Analysis of the results presented in Table 3 indicates that there are differences in the evaluation of the impact of the defined features of a manager on the level of trust in employees with regard to the size of enterprises. The features of managers that evoked trust in them in large enterprises were self-improvement of knowledge, keeping secrets, tendency to trust and the acknowledgement that trust is a significant source of competitive advantage. In turn, managers evoking trust in themselves in medium-sized firms were characterized by the 
conviction that it is the source of innovativeness and competitive advantage. However, in small firms the features influencing trust were the reduction of collateral with regard to longterm clients and the conviction that the majority of people are open. In micro-sized firms the ability to keep secrets was valued the most in managers.

Table 3 - Features of managers influencing the level of trust shown to them with relation to the size of an enterprise in percentage form

\begin{tabular}{|l|l|l|l|l|l|}
\hline Features & Total & Micro & Small & Medium & Large \\
\hline Self-improvement of knowledge & 64 & 52 & 53 & 65 & 87 \\
\hline They keep secrets & 66 & 62 & 65 & 62 & 76 \\
\hline They reduce collateral with regard to long-term clients & 53 & 45 & 74 & 60 & 32 \\
\hline They have a high tendency to trust others & 32 & 10 & 37 & 29 & 42 \\
\hline $\begin{array}{l}\text { They are of the opinion that the majority of people are } \\
\text { open }\end{array}$ & 38 & 42 & 46 & 25 & 39 \\
\hline $\begin{array}{l}\text { They are of the opinion that trust is an important } \\
\text { competitive advantage }\end{array}$ & 54 & 47 & 53 & 60 & 55 \\
\hline $\begin{array}{l}\text { They are of the opinion that trust is an important source of } \\
\text { innovativeness }\end{array}$ & 55 & 48 & 56 & 67 & 50 \\
\hline
\end{tabular}

If the managers undertake action that is aimed at building trust in the organization, it is possible to refer to the orientation towards the creation of trust in such a case. With the aim of identifying the degree of occurrence of this orientation in the activities of managers, the indications of a research model by $J$. Paliszkiewicz ${ }^{12}$ with relation to the orientation of a manager towards the creation of trust and the orientation of enterprises towards the creation of culture based on trust were utilized. The general level of orientation towards the creation of trust is at a level that is higher than 50, while simultaneously no significant differences exist between enterprises in terms of activities on behalf of creating trust with regard to their size (orientation of managers towards creating trust and enterprises towards creating organizational culture were measured on a scale from 15 to75)

Strengthening the orientation towards trust in an enterprise is the result of increased trust in managers and co-workers. The research conducted by the authors at hand indicates that there is a significant dependency between the indicators of the orientation towards the creation of trust and the level of trust in managers. One of the significant ones is the impact on the level of motivation of employees $\left(\mathrm{r}_{\mathrm{s}}=0,419\right.$, at $\left.\mathrm{p}=0,05\right)$. The greater the level of trust in managers, the greater the level of motivation of employees. Another indicator that illustrates a significant relation is the feeling of responsibility $\left(r_{s}=0393\right.$, at $\left.p=0,05\right)$. The greater the level of trust shown by the employees to the manager, the more responsible they feel about their task and there is no need to monitor them. Likewise, being helpful with regard to other 
employees is dependent on the level of trust in employees $\left(r_{s}=0397\right.$, at $\left.p=0,05\right)$. A further indicator that illustrates a significant correlation with the level of trust bestowed on the manager is the ability to keep promises $\left(r_{s}=0370\right.$, at $\left.p=0,05\right)$. The greater the level of trust in the firm, the greater the number of employees keeping promises. Openness associated with the possibility of speaking about what you do not like, or something that needs to be changed is significantly dependent on the level of trust in managers $\left(r_{s}=0358\right.$, at $\left.p=0,05\right)$. The impact on the level of trust in managers is associated with their fulfilment of the role of advisors and intellectual partners with regard to their subordinates $\left(r_{s}=0370\right.$, at $\left.p=0,05\right)$.

Slightly different indicators of the orientation towards the creation of trust are correlated with trust in employees. The most important of these may include keeping promises $\left(r_{s}=0,458\right.$, at $p=0,05)$. The greater the level of trust in employees, the greater degree of employees keeping promises. A relatively high indicator of the correlation exists between trust in employees and the claim that employees in a firm try to be helpful to others most of the time and do not only think of their self-interests $\left(r_{s}=0,416\right.$, at $\left.\mathrm{p}=0,05\right)$. Thus, trust favours the building of the employee collective. Apart from the factors that positively strengthen the level of trust between employees, there are also indicators that are negatively correlated with this. The most important of these include the claim that nowadays you can only count on yourself in a firm and only trust yourself $\left(r_{s}=-0,451\right.$, at $\left.p=0,05\right)$. Likewise, the claim that contacts between employees in a firm are mainly based on conflicts and rivalry is negatively correlated with trust $\left(r_{s}=-0,396\right.$, at $\left.\mathrm{p}=0,05\right)$. These indicators are characteristic of individualistic attitudes. The claim that the employees of a company will be dishonest when the opportunity arises is negatively correlated with trust $\left(r_{s}=-0,402\right.$, at $\left.p=0,05\right)$. The lack of faith in the honesty of others favours the creation of individualistic attitudes.

Long-lasting trust with regard to managers and co-workers may become the basis for the creation of organizational culture based on trust which fulfils the function of the cultural norm in the organization. The level of trust in the members of a particular organization, as well as the evaluation of others, to what degree they can rely on the others who they work with constitute an important parametric indicator in terms of the occurrence of the culture of trust. The general level of the orientation towards the creation of the culture of trust is at a higher level in large enterprises - 51,1. There is a relatively lower orientation towards the culture of trust in small enterprises - 46,9 (orientation of managers towards creating trust and enterprises towards creating organizational culture were measured on a scale from 15 to 75). 
The formation of the culture of trust may be referred to when the indicators are positively correlated with the level of trust in the manager and in the employees. The strongest correlation occurred between trust in the managers and taking care of the interests of the employees $\left(r_{s}=0,607\right.$, at $\left.p=0,05\right)$, good relations between employees $\left(r_{s}=0,504\right.$, at $p=$ $0,05)$, atmosphere of cooperation $\left(\mathrm{r}_{\mathrm{s}}=0,499\right.$, at $\left.\mathrm{p}=0,05\right)$ and sharing knowledge $\left(\mathrm{r}_{\mathrm{s}}=0,474\right.$, at $\mathrm{p}=0,05)$. Hence, it is possible to formulate the conclusion that the greater the level of trust enjoyed by the manager with regard to the employees, the greater the level of the culture of trust in the enterprise. The weakest correlation occurred between trust in the manager and the clearly defined expectations of the employees relating to results and targets $\left(r_{s}=0,256\right.$, at $p=$ 0,05). Likewise, the culture of trust also appears in employee relations. Research indicates that the strongest correlation occurred between trust in other employees and the atmosphere of cooperation $\left(r_{s}=0,546\right.$, at $\left.p=0,05\right)$, good relations between employees $\left(r_{s}=0,494\right.$, at $p=$ $0,05)$, sharing knowledge $\left(\mathrm{r}_{\mathrm{s}}=0,472\right.$, at $\left.\mathrm{p}=0,05\right)$ and taking care of the interests of the employees $\left(r_{s}=0,478\right.$, at $\left.\mathrm{p}=0,05\right)$.

\section{Conclusions}

The results of research show that significant differences exist between trust in employees and in managers. Relatively low levels of trust in employees have been identified. This is evidence of low social capital, which has an unfavourable impact on the market situation of enterprises.

Coordinated activities are becoming a necessity, which over a long-term period would enable the achievement of a high level of trust among employees. Such an action may become the orientation towards the formation of organizational culture in which trust plays a significant role. The research carried out by the authors at hand illustrate that large enterprises are featured by the highest level in terms of the realization of the orientation towards the culture of trust, while the lowest level was identified in small firms. It is possible to assume that one of the reasons is the observance of the importance of long-term activities to create trust and make it an organizational norm by the managerial staff in large enterprises. Managers in their activities on behalf of developing trust may take three fundamental factors into account, namely: historical tradition of the particular enterprise which is reflected in the organizational culture; the structural context of the organization that includes among others, normative cohesion, stability of the organizational order, transparency of the organizational culture, social responsibility of the organization), subjective equipment that consists of the social 
moods of the employees (optimism, orientation of the future, orientation towards success, professional aspirations) and social capital resources (certainty of employment, high qualifications, job security, multiplicity of roles, network of social ties, etc.

\section{References}

1. P. Sztompka, Zaufanie. Fundament społeczeństwa, Znak, Kraków, 2007.

2. J.S. Coleman, Foundation of social theory, Belknap Press Cambridge, London, 1990.

3. M. Bugdol, Wymiary i problemy zarządzania organizacją opartą na zaufaniu, Wydawnictwo Uniwersytetu Jagiellońskiego, Kraków 2010.

4. P. Kenning, Customer Trust Management: Ein Beitrag zum Vertrauensmanagement im Lebensmitteleinzelhandel, Deutscher Universitats - Verlag, Wiesbaden, 2002.

5. L.S. Cummings, P. Bromiley, The organizational trust inventory (OTI): Development and validation, in R.M. Kramer and T.R. Tyler (ed.), Trust in Organizations: Frontiers of Theory and Research. Sage, Thousand Oaks, 1996, 302-330.

6. J.A. Gilberth, T.L.P.,Tang, An Examination of Organizational Trust Antecedents, Public Personnel Management, 27 (1998) 321-338.

7. T. Gillis, More Than a Social Virtue: Public trust among organizations most valuable asset, Communication World, 20 (2003)10-12

8. P.M. Doney, J.P. Cannon, An examination of the nature of trust in buyer-seller relationships, Journal of Marketing 61 (1997) 35-51

9. T. Grandison, M. Sloman, Specifying and analysing trust for internet applications. URL: http://www.doc.ic.ac.uk/ (30.04.2017)

10. Jøsang, C. Keser, T. Dimitrakos, Can We Manage Trust? in: Trust Management, The Proceedings of the 3rd International Conference on Trust Management, Paris 2005 http://folk.uio.no/josang/papers/JKD2005-iTrust.pdf (10.05.2017)

11. R.J. Lewicki, D.J McAllister, R.J. Bies, Trust and distrust: new relationships and realities, Academy of Management Review 23 (1998) 438-458

12. Paliszkiewicz, J. (2013). Zaufanie w zarządzaniu. Warszawa: Wydawnictwo Naukowe PWN. 